\title{
ANALISIS SEBARAN MINERAL LOGAM PADA SEDIMENTASI BATUAN DI DAERAH KERTAJADI, CIDAUN, KABUPATEN CIANJUR, JAWA BARAT MENGGUNAKAN METODA GEOMAGNET
}

\author{
Rajab Arief Basuki ${ }^{1}$, Nanang Dwi Ardi ${ }^{*}$, Mimin Iryanti ${ }^{1}$ \\ ${ }^{1)}$ Departemen Pendidikan Fisika, FPMIPA, Universitas Pendidikan Indonesia \\ Jl. Dr. Setiabudhi No. 229, Bandung dan 40154
}

*Penulis Penanggungjawab. Email : rajab.arief@outlook.com

\begin{abstract}
ABSTRAK
Cidaun merupakan salah satu daerah pesisir pantai selatan yang terletak pada Kabupaten Cinajur Provinsi Jawa Barat. Salah satu kelebihan dari daerah pesisir pantai selatan Pulau Jawa adalah terdapat banyaknya mineral logam penghasil besi yang tersebar luas di sepanjang pesisir pantai. Oleh karena itu dilakukanlah eksplorasi untuk memetakan sebaran mineral logam yang ada di daerah Cidaun. Dalam melakukan eksplorasi mineral logam dibutuhkan suatu metode yang paling efektif yaitu eksplorasi geofisika dengan menggunakan metode geomagnet. Proses pengolahan data pada metode geomagnet dilakukan dengan menghitung nilai anomali magnetik dari medan magnetik total yang telah dilakukan koreksi terhadap koreksi harian dan koreksi IGRF. Kemudian dengan metode inversi data yang telah didapat dijadikan sebuah model. Selain itu dilakukan juga interpretasi kualitatif dan interpretasi kuantitatif. Interperetasi kualitatif dilakukan pada data yang telah dimodelkan menggunakan software surfer 11, apabila data tersebut terdapat anomali magnetik bernilai sangat tinggi yang berdekatan dengan nilai anomali magnetik bernilai rendah atau perubahan nilai anomali terjadi secara signifikan kemudian dilakukan proses interpretasi secara kuantitatif. Interpretasi kuantitatif pada penelitian ini dengan dilakukan deliniasi berupa proses sayatan pada perbedaan nilai anomali magnetik yang terjadi perubahan secara signifikan. Tahap selanjutnya data dari proses sayatan tersebut kemudian dilakukanlah pemodelan menggunakan software mag2dc untuk mengetahui sebaran mineral logam dapa daerah tersebut. Berdasarkan data yang telah diolah pada daerah Kertajadi, Cidaun, Kabupaten Cianjur, Jawa Barat dengan koordinat 698283 easting - 757162 easting dan 9180169 northing - 9171050 northing memiliki rentang nilai anomali magnetik -5 nT - 145 nT. Sedangkan nilai anomali magnetik pada daerah yang telah dilakukan proses sayatan memiliki rentang nilai $84.18 \mathrm{nT}$ - $119.69 \mathrm{nT}$ dengan nilai susptibilitas $-0.041000-0.050001$. Dari rentang nilai suseptibilitas tersebut diduga sebaran mineral yang yang memiliki nilai suseptibilitas positif merupakan bijih besi sedangkan yang bernilai negatif
\end{abstract}


merupakan lempung dan endapan pasir. Dari hasil dari penelitian ini diharapkan data tersebut dapat dijadikan informasi dan referensi bagi masyarakat, peneliti lain dan pengusaha tambang dalam eksplorasi mineral logam.

Kata Kunci: Cidaun, Mineral logam, Metode magnetik, Anomali Magnetik, Susptibilitas, Bijih Besi

\begin{abstract}
Cidaun is one of the coastal areas of the southern coast located in the district of West Java province Cinajur. One of the advantages of the southern coastal areas of Java is that there are many ferrous metal mineral producer widespread along the coast. Therefore, the exploration was undertaken to map the distribution of metallic minerals in the area Cidaun. In conducting metal mineral exploration required a most effective method is a geophysical exploration using geomagnetic methods. Data processing on geomagnetic method is done by calculating the value of the magnetic anomalies of the total magnetic field has a daily correction of correction and correction IGRF. Then, with the inversion method of data has been obtained serve as a model. The researcher also interpretation of qualitative and quantitative interpretation. Qualitative Interperetasi performed on the data that has been modeled using software surfer 11 , when the inputs are very high-value magnetic anomalies adjacent to the value of the magnetic anomalies of low value or change in value of the anomaly occurred significantly later performed quantitative interpretation process. Quantitative interpretation in this study conducted a process of delineation of the incision on the difference in magnetic anomaly change significantly. The next stage of the data are then perform the incision process modeling using software mag2dc to determine the distribution of metallic minerals onshore areas. Based on the data that has been processed in the region Kertajadi, Cidaun, Cianjur, West Java coordinate 698283 easting - 757162 easting and 9180169 northing - 917105 northing and has a value range of magnetic anomaly $-5 \mathrm{nT}-145 \mathrm{nT}$. While the value of magnetic anomalies in the area that has been carried out the process of incisions have a range of values $84.18 \mathrm{nT}-119.69 \mathrm{nT}$ with susptibilitas value $-0.041000-0.050001$. Of the value range susceptibility is suspected distribution of minerals that have a positive susceptibility value is the iron ore which is negative while the clay and sand deposits. From the results of this study are expected data can be made of information and reference for the community, other researchers and mining company in mineral exploration.
\end{abstract}

Keywords: Cidaun, Minerals metals, magnetic method, Magnetic Anomaly, Susptibilitas, Iron Ore 


\section{Pendahuluan}

Cidaun merupakan salah satu daerah pesisir pantai selatan yang terletak pada Kabupaten Cinajur Provinsi Jawa Barat. Salah satu kelebihan dari daerah pesisir pantai selatan Pulau Jawa adalah terdapat banyaknya mineral logam penghasil besi yang tersebar luas di sepanjang pesisir pantai. Berdasarkan data pada peta geologi lembar Sindangbarang dan Bandar Waru Koesmono 1976, daerah Cidaun memiliki struktur geologi berupa aluvium dan endapan pantai yang terdiri dari lempung, lanau, pasri dan kerikil. Pasir pantai pada daerah Cidaun memiliki konsentrasi mineral logam dengan rata-rata hingga 57\% Fe dan 16\% TiO2. Oleh karena itu dilakukanlah eksplorasi untuk memetakan sebaran mineral logam yang ada di daerah Cidaun. Dalam melakukan eksplorasi mineral logam dibutuhkan suatu metode yang paling efektif untuk memenuhi eksplorasi tersebut. Dan metode yang digunakan oleh peneliti dalam penelitian ini adalah metode geomagnet.

Penelitan yang menggunakan metode geomagnet memanfaatkan parameter suseptibilitas batuan untuk menginterpretasikan struktur bawah bumi. Pengolahan data dilakukan dengan metode inversi, dalam metode ini data dijadikan sebuah model untuk mendapatkan beberapa parameter fisis struktur bawah permukaan daerah yang ditinjau (Sampurno, 2013). Selain itu dilakukan juga interpretasi kualitatif dan interpretasi kuantitatif. Secara kualitatif terdapat anomali magnetik bernilai sangat tinggi yang berdekatan dengan nilai anomali magnetik bernilai rendah dimana $\begin{array}{llr}\text { perubahannya } & \text { terjadi } & \text { secara } \\ \text { signifikan. } & \text { Secara } & \text { kuantitatif } \\ \text { dilakukan } & \text { deliniasi } & \text { dengan } \\ \text { dilakukannya } & \text { proses sayatan pada } \\ \text { perbedaan } & \text { anomali } & \text { tersebut. }\end{array}$ (Massinai, 2014)

Dalam penilitian ini pengambilan data yang telah dilkukan pada eksplorasi geomagnet berbeda dengan dengan penelitian Siti Rusita, 2016. Pengambilan data dilakukan secara semi-looping dan semi-line perbedaan dari proses ini yaitu menggunakan 3 base data dan dilakukan menyerupai line dan berujung pada looping.

Dalam Proses pengolahan data pada metode geomagnet dilakukan dengan menghitung nilai anomali magnetik dari medan magnetik total yang telah dilakukan koreksi terhadap koreksi harian dan koreksi IGRF. Kemudian dengan metode inversi data yang telah didapat dijadikan sebuah model. Selain itu dilakukan juga interpretasi kualitatif dan interpretasi kuantitatif. Interperetasi kualitatif dilakukan pada data yang telah dimodelkan menggunakan software surfer 11 , apabila data tersebut terdapat anomali magnetik bernilai sangat tinggi yang berdekatan dengan nilai anomali magnetik bernilai rendah atau perubahan nilai anomali terjadi secara signifikan kemudian dilakukan proses interpretasi secara kuantitatif. Interpretasi kuantitatif pada penelitian ini dengan dilakukan deliniasi berupa proses sayatan pada perbedaan nilai anomali magnetik yang terjadi perubahan secara signifikan. Tahap selanjutnya data dari proses sayatan tersebut kemudian dilakukanlah modeling menggunakan software 
mag2dc untuk mengetahui sebaran mineral logam dapa daerah tersebut.

\section{Metode Penelitian}

Penelitian ini dilakukan dengan mengikuti diagram alur seperti berikut:

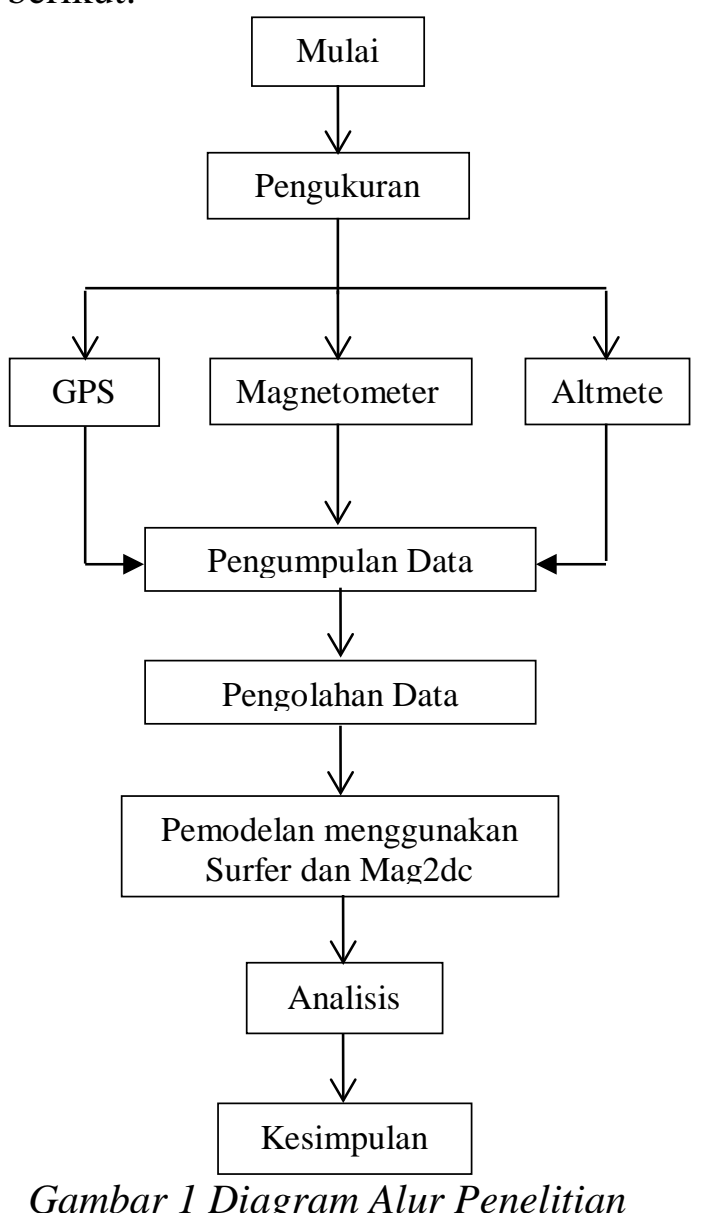

Pengukuran dilakukan secara SemiLine dan Semi-Looping yaitu pengukuran yang dilakukan menyerupai pola garis lurus dan setengah lingkaran yang bertujuan mengikuti jalur yang tersedia yang memungkinkan untuk dapat dilewati saat pengambilan data. Pengukuran ini terdiri dari 3 base station yang berbeda dan berujung membentuk menyerupai pola looping. Lintasan pengambilan data menggunakan 2 lintasan Semi-Line dan 1 lintasan
Semi-Looping, dimana lintasan 1 disebelah Utara bermulai dari arah Timur menuju Barat dan membentuk sebuah lintasan Semi-Line dari base station 1 sampai base station 2 . Untuk lintasan 2 bermulai dari sebelah Utara menuju Selatan dan melingkar ke Barat membentuk sebuah lintasan Semi-Looping dari base station 2 sampai base station 3 . Sedangkan untuk lintasan 3 disebelah selatan bermulai dari arah Barat menuju Timur dan membentuk sebuah lintasan Semi-Line dari base station 3 sampai titik akhir pengukuran.

Setelah melakukan pengukuran proses selanjutnya adalah pengumpulan data, tahap ini data yang dicatat saat pengukuran pada GPS, magnetometer dan altimeter dikumpulkan menggunakan software Microsoft Excel dan disesuaika berdasarkan titik stasiun.

Setelah melakukan proses pengumpulan data kemudian memasuki proses pengolahan data. data pengukuran di titik stasiun disesuaikan berdasarkan kebutuhan, data koordinat pada GPS yang berbentuk data geografis dirubah menjadi data UTM, data medan magnet total pada magnetometer dilakukan beberapa koreksi seperti IGRF dan koreksi harian sehingga menghasilkan anomali magnetik pada setiap titik stasiun. Dari data anomali magnetik kemudian diolah untuk mendapatkan susptibilitas untuk proses identifikasi mineral pada daerah eksplorasi.

Setelah proses pengolahan data proses selanjutnya adalah pemodelan. Dari data hasil pengolahan data dilakukan pemodelan menggunakan software 
surver 11 untuk mendapatkan peta kontur anomali medan magnet. Pada peta tersebut dilakukan proses sayatan yang diduga terjadi anomali atau adanya perubahan nilai magnetic secara signifikan pada peta anomali medan magnet. Data dari proses sayatan tersebut kemudian dimodelkan kembali dengan software Mag2dc untuk melihat dugaan sebaran mineral pada daerah sayatan.

Tahap terakhir adalah analisis data, pada tahap ini data identifikasi mineral logam dan sebarannya dianalisis yang kemudian didapatkan hasil dari peniltian yang telah dilakukan.

\section{Koreksi Harian}

Koreksi harian (diurnal correction) merupakan penyimpangan nilai medan magnetik bumi akibat adanya perbedaan waktu dan efek radiasi matahari dalam satu hari.

Waktu yang dimaksudkan harus mengacu atau sesuai dengan waktu pengukuran data medan magnetik di setiap titik lokasi (stasiun pengukuran) yang akan dikoreksi. Apabila nilai variasi harian negatif, maka koreksi harian dilakukan dengan cara menambahkan nilai variasi harian yang terekan pada waktu tertentu terhadap data medan magnetik yang akan dikoreksi. Sebaliknya apabila variasi harian bernilai positif, maka koreksinya dilakukan dengan cara mengurangkan nilai variasi harian yang terekan pada waktu tertentu terhadap data medan magnetik yang akan dikoreksi.

\section{Koreksi IGRF}

Data hasil pengukuran medan magnetik pada dasarnya adalah konstribusi dari tiga komponen dasar, yaitu medan magnetik utama bumi, medan magnetik luar dan medan anomali. Nilai medan magnetik utama tidak lain adalah niali IGRF. Jika nilai medan magnetik utama dihilangkan dengan koreksi harian, maka kontribusi medan magnetik utama dihilangkan dengan koreksi IGRF. Koreksi IGRFdapat dilakukan dengan cara mengurangkan nilai IGRF terhadap nilai medan magnetik total yang telah terkoreksi harian pada setiap titik pengukuran pada posisi geografis yang sesuai.

\section{Anomali Medan Magnet}

Untuk mendapatkan nilai anomali intensitas medan magnet yang menjadi taret survei, maka data manetik yang telah diperoleh dari hasil pengukuran lapangan harus dikoreksi dari adanya pengaruh beberapa medan magnet yang lain yaitu koreksi medan utama magnet bumi (IGRF) untuk menghilangkan pengaruh medan magnet yang berasal dari inti bumi dan koreksi variasi harian.

\section{Hasil Dan Pembahasan}

Studi Pendahuluan

Dalam tahapan ini peneliti mempelajari struktur geologi pada tempat penelitian untuk mengetahui kandungan mineral, batuan dan endapan yang ada pada daerah tersebut. Lokasi penelitian berada pada Daerah Kertajadi, Cidaun, Kabupaten Cianjur, Jawa Barat yang merupakan daerah pesisir pantai selatan dengan struktur geologi yang tampak adalah pasir pantai, lempung dan kerikil yang menyebar hampir diseluruh lokasi penelitian. Pada lokasi penelitian terdapat perbedaan kepadatan yang mempengaruhi 
kekerasan tanah pada daerah tersebut, hal itu diduga karena terjadinya pengikisan oleh air laut dan perbedaan waktu endapan pada daerah tersebut. Di beberapa tempat pada lokasi penelitian terdapat bongkahan batu yang salah satu dari bongkahan tersebut memiliki warna kehitaman yang diduga mengandung mineral besi.

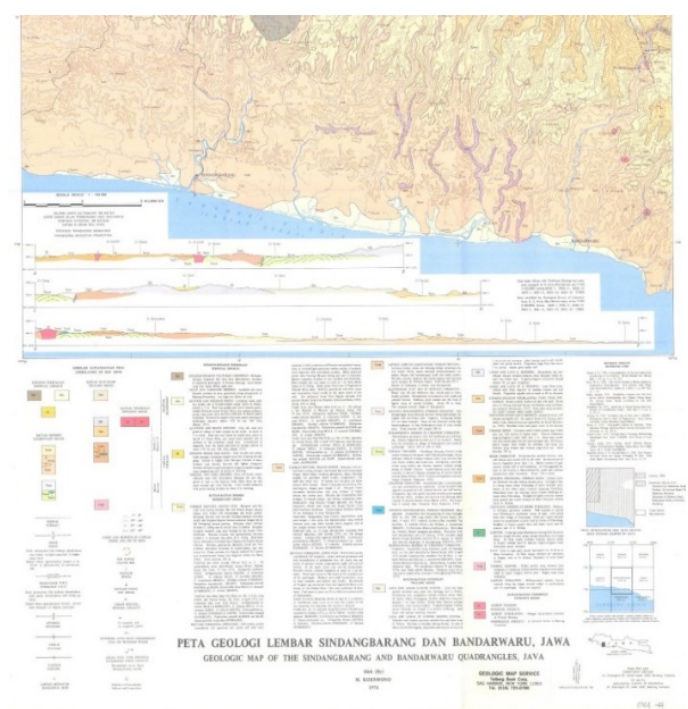

Gambar 2 peta Geologi

Setelah mempelajari struktur geologi pada tempat penelitian, peneliti juga mempelajari topografi agar dapat menentukan titik-titik pengukuran. Hal tersebut dilakukan agar proses pengambilan data tidak meluas ke daerah yang tidak diinginkan dan untuk menghindari daerah- daerah yang sekiranya sulit untuk di lalui saat pengambilan data.

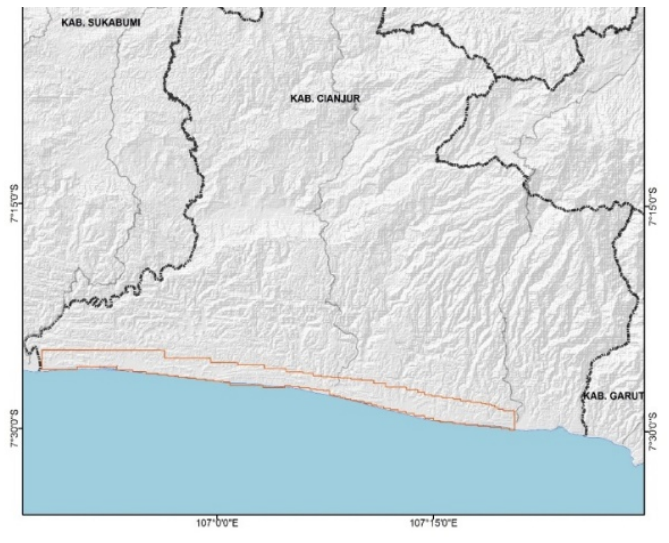

Gambar 3 peta topografi

Menentukan Titik Pengukuran

Tahap selanjutnya sesuai dengan yang telah dipaparkan pada tahap awal, pada tahap ini dilakukan pembatasan wilayah dan penentuan titik - titik pengukuran agar proses pengambilan data tidak meluas ke daerah yang tidak diinginkan dan untuk menghindari daerah- daerah yang sekiranya sulit untuk di lalui saat pengambilan data.

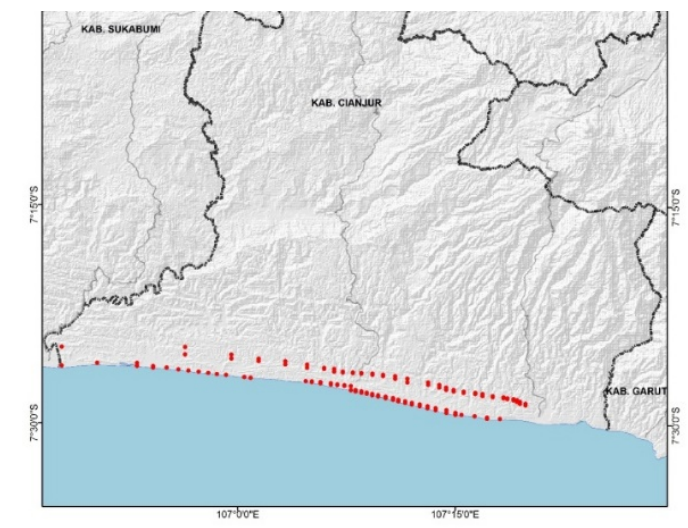

Gambar 4 titik pengukuran

Koreksi Harian

Koreksi ini dimaksudkan untuk mandapatkan anomali magnetik yang tidak dipengaruhi efek medan luar (aktifitas matahari). Aktifitas matahari pada waktu siang hari dapat 
menyebabkan terionisasinya electron

- elektron yang ada di atmosfir bumi yang berakibat akan timbulnya medan magnet sekunder yang kemudian akan terdeteksi pada alat yang telah digunakan saat melakukan pengukuran.

Koreksi harian dilakukan dengan menggunakan data pengukuran medan magnet di lapangan dengan pengukuran di titik ikat dan diukur secara berkala. Harga pembacaan medan magnet dititik ikat di interpolasikan agar sesuai dengan waktu pengukuran medan magnet dilapangan. Konstanta koreksi harian ditentukan dengan cara mengambil harga rata-rata dari keseluruhan harga pembacaan dititik ikat.

\section{Koreksi IGRF}

Koreksi IGRF dilakukan dengan cara menggunakan data nilai medan magnet utama bumi di daerah penelitian yang didapat melalui pendekatan matematis dari intensitas magnet utama bumi atau IGRF (Internasional Geomagnetic Refference Field) terhadap medan magnet bumi total di titik pengamatan. Data IGRF dapat diperoleh melalui website https://www.ngdc.noaa.gov/geomagweb/?model=igrf\#igrfwmm.

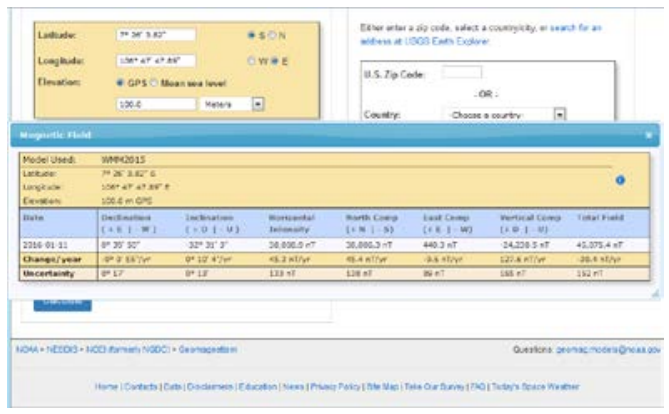

Gambar 5 tampilan Website untuk menentukan IGRF

Pengolahan dan Analisis Data

Peta anomali magnetik yang merupakan gambaran sebaran mineral logam pada daerah Kertajadi, Cidaun, Kabupaten Cianjur, Jawa Barat dibuat dengan menggunakan Software Surfer 11 sedangkan untuk perhitungannya menggunakan Software Microsoft Excell 2010. berikut adalah peta anomali magnetik yang diperoleh dari medan magnet total yang telah dilakukan koreksi harian dan koreksi IGRF.

Berdasarkan gambar 6 anomali magnetik dari rentang warna biru hingga ungu adalah laut dan rentang berwarna hijau hingga putih adalah daratan. Dari gambar 6 pula didapat adanya nilai anomali tinggi yang berdampigan dengan nilai anomali rendah yg diduga adanya anomali pada daerah tersebut, sehingga pada daerah tersebut dilakukanlah proses sayatan dari arah barat ke arah timur dari koordinat 743174.09687072 easting dan 9174967.9390259 Southing hingga koordinat 756445.5751912 easting dan 9173266.4674464 Southing dengan rentang suseptibilitas $84.178 \mathrm{nT}$ $119.69 \mathrm{nT}$. 


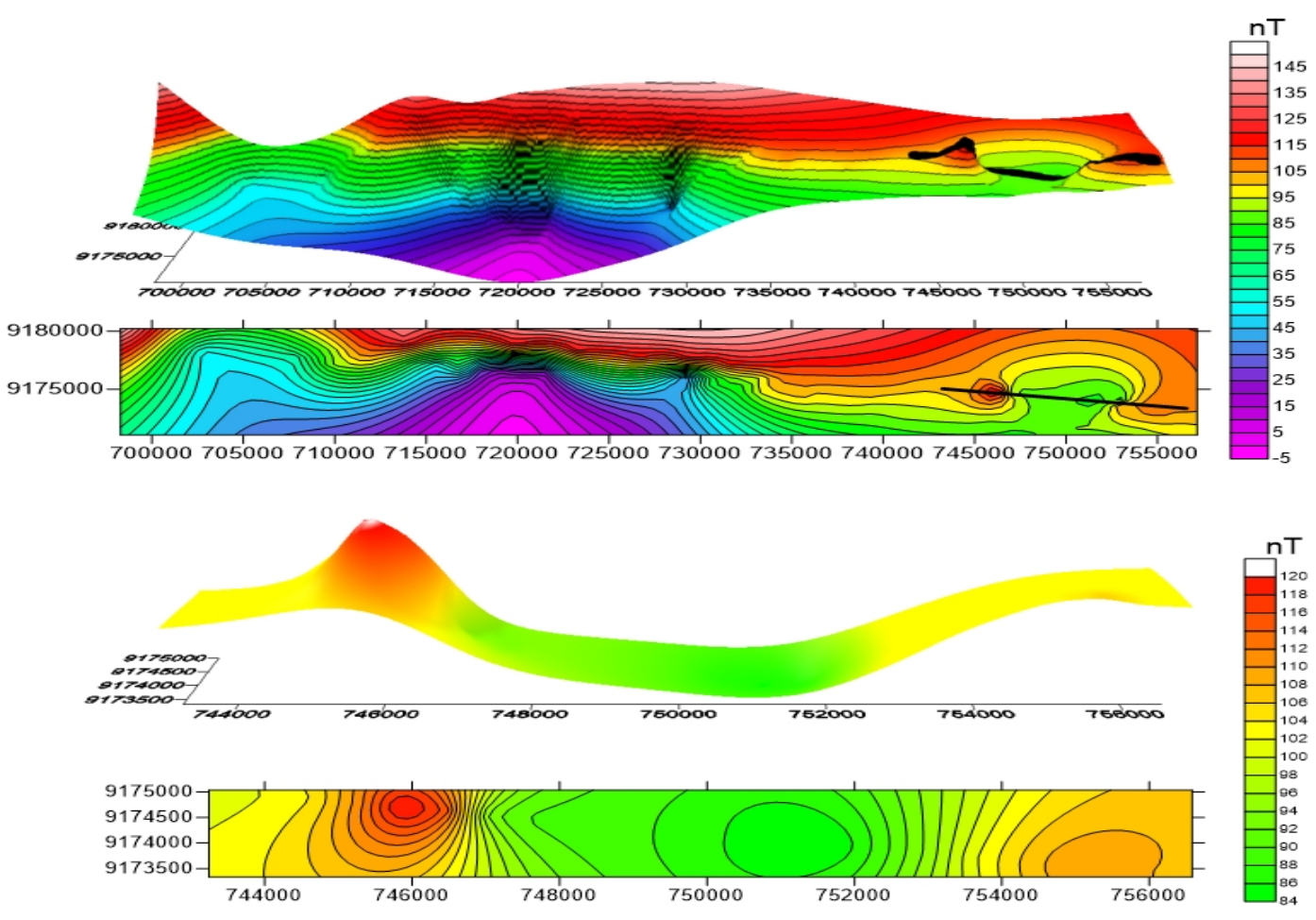

Gambar 6 Peta Anomali Magnetik Setelah Dikoreksi

Data pada proses Sayatan kemudian diolah dan digambarkan menggunakan Sofware mag2dc untunk dilihat kemungkinan batuan didalam daerah yang telah dilakukan proses Sayatan dan diketahui susptibilitasnya, seperi yang telah digambarkan.

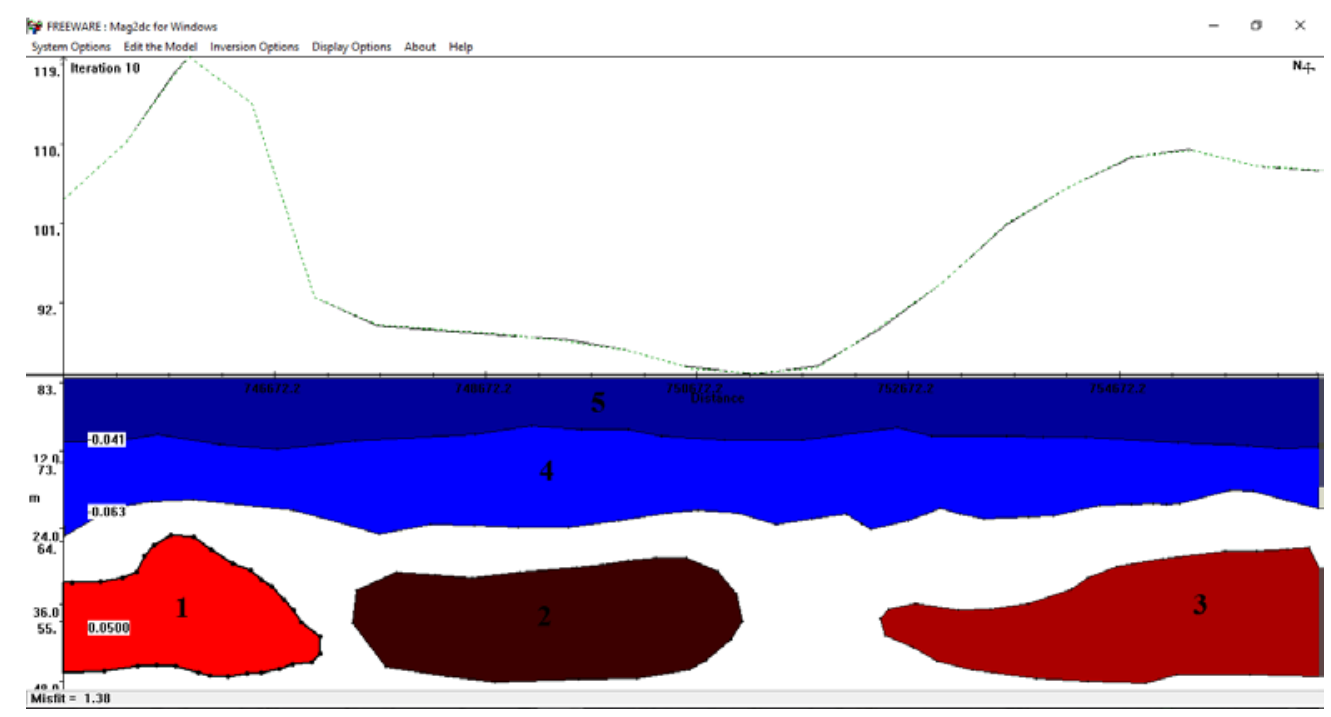


Dari gambar diatas diketahui dugaan mineral yang terseberar sebanyak 5 bongkahan dengan nilai susptibilitas bongkahan 1 sebesar 0.050001 pada kedalaman 25 meter, bongkahan 2 sebesar 0.006524 pada kedalaman 28 meter, bongkaha 3 sebesar 0.030992 pada kedalaman 27 meter, bongkahan 4 sebesar -0.063550 pada kedalaman 4 meter dan bongkahan 5 sebesar 0.041000 pada kedalaman 1 meter. sehingga rentangnya susptibilitas sebesar $-0.041000-0.050001$ dari arah barat hingga timur dan dari kedalaman sekitas 1 - 28 meter di bawah tanah. Dari nilai susptibilitas tersebut diketahui bahwa mineral yang terkandung dalam bongkahan 1 hingga bongkahan 3 pada daerah di bawah permukaan garis sayatan mengandung mineral logam atau bijih besi.

\section{Simpulan}

Berdasarkan data yang telah olah pada daerah Kertajadi, Cidaun, Kabupaten Cianjur, Jawa Barat memiliki rentang nilai anomali magnetik -5 nT - 145 nT. Sedangkan sebaran mineral logam pada daerah sayatan di lokasi penelitian terbentang pada arah barat menuju timur dengan nilai anomali magnetik pada rentang nilai $84.18 \mathrm{nT}$ - $119.69 \mathrm{nT}$ dengan nilai susptibilitas $-0.041000 \quad-$ 0.050001. Dari rentang nilai suseptibilitas tersebut diduga sebaran mineral yang yang memiliki nilai suseptibilitas positif merupakan bijih besi sedangkan yang bernilai negatif merupakan lempung dan endapan pasir.

\section{Referensi}

1. Bilalodin (2010) Kajian Sifat Magnetik Dari Pasir Besi Pantai Logending Kabupaten Kebumen, Program Studi Fisika, Jurusan MIPA Fakultas Sains dan Teknik, Universitas Jenderal Soedirman Purwokerto

2. Burger, H.R.,Sheehan, Anne F., Jones, Craig H., (2006) Introduction to Apllied Geophysiscs, W.W. Norton \& Company, New York

3. Dobrin, M.B. dan Savit, C.H., 1988, Introduction to Geophysisc Prospecting 4th Edition, New York.

4. Elisyah, H. (2015) Identifikasi Sebaran dan Ketebalan Pasir Besi Daerah Pantai Glagah Indah Siderejo, Temon, Kabupaten Kulon Progo D.I. Yogyakarta Dengan Menggunakan Metode Geomagnetik (Skripsi). Program Studi Fisika, Fakultas Sains dan Teknologi, Universitas Sunan Kalijaga, Yogyakarta.

5. Koesmono (1976) peta geologi lembar Sindangbarang dan Bandar Waru. Direktorat Geologi. Jalan Dipenegoro 57 Bandung.

6. Massinai, M. A. dkk (2014) Penetapan Metode Geomagnet Dalam Pendugaan Potensi Laterit Bijih Besi di 
Pangalasiang Donggala,

Makasar, Prodi Geofisika FMIPA

UNHAS Makasar

7. NOAA (2016) Magnetic Field Calculators. [Online].

Tersedia https://www.ngdc.noaa. gov/geomag-

web/?model=igrf\#igrfwmm. Diak

ses 20 Oktober 2016

8. Perkins, D. (2002) Mineralogy 2nd Edition. Prentice-Hall Inc, New Jersey. United Stated of America.

9. Rauf, Abdul (2012) Miineralisasi Bijih Besi di Kabupaten Donggala Provinsi Sulawesi Tengah. UPN Veteran, Yogyakarta.

10. Rusita, Siti dkk (2016) Identifikasi Sebaran Bijih Besi Dengan Metode Geomagnet di Daerah Pemalongan, Bajuin Tanah Laut, 1916-3965-1-SM

11. Sampurno, J. (2013) Aplikasi Metode Magnetik Untuk Eksplorasi Bijih Besi Studi Kasus : Bukit Munung Kabupaten Bengkayang, Kalimantan Barat, 598-2019-1-PB

12. Telford, W.M., Geldart, L.P dan

Sheriff, R.E. (1990). Applied

Geophysics. Second Edition.

Cambridge: Cambridge

University Press. 